\title{
Top management teams and the performance of entrepreneurial firms
}

\author{
Kathleen M. Eisenhardt
}

Accepted: 11 February 2013/Published online: 16 March 2013

(C) Springer Science+Business Media New York 2013

\begin{abstract}
This article examines why some entrepreneurial firms succeed while others do not. The focal explanation is top management teams, including several studies that address when and how top management teams are likely to influence entrepreneurial firm performance. There are several insights. First, large and diverse teams with a history of working together are more likely to succeed. This effect is particularly large when they launch in growth markets. Second, teams are effective in making strategic decisions when they are fast, highly conflictual, and still get along. Third, they are also effective when they rely on "simple rules" heuristics to perform significant activities like new product development and internationalization that nonetheless happens often. A further insight is that these "simple rules" can become the strategy of their firms. Fourth, more effective teams continuously organize the structures of their firms at the "edge of chaos". Overall, top management teams emerge as central to the success (or lack thereof) of entrepreneurial firms.
\end{abstract}

Kathleen M. Eisenhardt is the 2012 Winner of the Global Award for Entrepreneurship Research. This essay is the Prize Lecture given upon receipt of the Award on 16 May 2012 in Stockholm, Sweden. For more information about the Prize and previous Winners see www.e-award.org.

K. M. Eisenhardt $(\bowtie)$

Department of Management Science and Engineering,

Stanford University, Stanford, CA, USA

e-mail:kme@stanford.edu
Keywords Entrepreneurship - Top management teams $\cdot$ Firm performance $\cdot$ Strategic decision making . Heuristics · Organizational structure · Organizational processes $\cdot$ Edge of chaos $\cdot$ Strategy as simple rules

JEL Classifications $\quad$ D22 $\cdot$ L10 $\cdot$ L25 $\cdot$ L26

\section{Introduction}

Why do some entrepreneurial firms succeed while others do not? Economics has long considered how industries emerge, evolve, and decline (e.g., Agarwal and Gort 2002). Similarly, sociology has long studied the entry and exit dynamics of populations of firms (e.g., Sine et al. 2005; Hiatt et al. 2009). In both of these disciplines, the emphasis is on the environment such as its competitiveness, geographical features, and institutional arrangements. Yet, despite extensive research, these disciplines have looked much less into why firms in seemingly similar environments often have very disparate performance outcomes. To give an example, many firms began in the social networking space of the mid-2000s. Yet, while clearly Facebook and LinkedIn have become stars, others such as MySpace have fallen away and still others simply never gained traction at all. Why? Are successful entrepreneurial firms merely lucky? Or are there organizational and strategic practices that effectively help some entrepreneurial firms to shape success? 
Research on strategy and organization suggests answers. For example, some entrepreneurial firms are more successful when they form attractive alliance portfolios (e.g., Baum et al. 2000; Ozcan and Eisenhardt 2009) or attract well-positioned, knowledgeable boards of directors (e.g., Gulati and Higgins 2003; Garg and Eisenhardt 2013). Others succeed when they introduce desirable products or quickly find viable business models (e.g., Zott and Amit 2010). Still others succeed when they have savvy strategies or top-notch employees (e.g., Beckman and Burton 2008; Eesley and Roberts 2012). Yet, while each of these explanations is likely to be true, they all rest on the same foundation, i.e., the top management team. After all, these executives are the ones who lead activities such as building alliance portfolios, developing new products, recruiting employees to the firm, and altogether oversee the myriad activities that shape entrepreneurial firm performance.

The aim of this paper is to synthesize evidence from several studies (i.e., two early and two recent) to sharpen when and how top management teams influence the performance outcomes of entrepreneurial firms. The first study uses statistical analysis of the population of entrepreneurial firms in the U.S. semiconductor industry to reveal how their initial top management teams, strategies, and markets influence their subsequent growth (Eisenhardt and Schoonhoven 1990). Although luck matters, the results also reveal the critical importance of founding top management teams for superior performance. The second study goes deeply into the firms themselves. Using inductive and multiple-case methods, it explores how top management teams in 12 entrepreneurial firms in the computer industry make strategic decisions (e.g., Eisenhardt and Bourgeois 1988; Eisenhardt 1989a; Eisenhardt et al. 1997). The results indicate the "winning trifecta" of speed, conflict, and getting along within top management teams. This trifecta shapes a better strategic decision process and ultimately superior entrepreneurial firm performance. Taken together, these early studies indicate a critical linkage among the characteristics of top management teams, strategic decision processes, and firm performance.

The third study combines statistical analyses with inductive, multiple-case studies to explore how top management teams learn as they engage in essential, repeated process activities such as developing new products, making acquisitions, and entering new countries (e.g., Bingham et al. 2007; Bingham and
Eisenhardt 2011). The setting is an in-depth examination of internationalization by 12 U.S., Singaporean, and Finnish entrepreneurial firms. The result is an understanding of the relevance of learning heuristics that we term "simple rules", rather than simply gaining experience, to strategy and firm performance. The fourth study takes a much different methodological approach. It combines computer-based simulation and mathematical modeling to explore how top management teams should structure their organizations to achieve high firm performance (Davis et al. 2009). The findings reveal that top management teams should poise at a structural "edge of chaos" to maintain superior performance, especially in the unpredictable markets that many entrepreneurial teams face. The findings also indicate the challenges of complex markets, attractiveness of high-velocity ones, and the extensive role that luck plays in highly ambiguous situations such as nascent markets.

Collectively, these four studies suggest the underlying mechanisms of team composition, strategic decision process, strategy as "simple rules", and structure at the "edge of chaos" by which top management teams shape the performance of their entrepreneurial firms. Collectively, these studies also reveal what might be termed my empirical approach, i.e., deep grounding in inductive, multiple-case theory building methods, complemented by statistical and simulation methods. The inductive, multiple-case methods use rich field data to generate insights into the behavioral processes within entrepreneurial firms (Eisenhardt 1989b; Eisenhardt and Graebner 2007). Statistical analyses reveal broad patterns in large-scale data that complement these case methods. Simulation enables computational experimentation to explore the insights gained from the other methods, especially when the phenomena are non-linear and relevant data are difficult or even impossible to obtain (Davis et al. 2007).

I conducted this research with outstanding collaborators. Kaye Schoonhoven was my primary partner in the investigation of the U.S. semiconductor industry (e.g., Eisenhardt and Schoonhoven 1990, 1996; Schoonhoven et al. 1990). Jay Bourgeois and I gathered the field data on the strategic decision making processes of entrepreneurial teams, and published several papers jointly (e.g., Bourgeois and Eisenhardt 1988; Eisenhardt and Bourgeois 1988; Eisenhardt et al. 1997) in addition to my sole-authored work 
(Eisenhardt 1989a, 1990). I worked with Christopher Bingham and Nathan Furr in the study of simple rules (e.g., Bingham et al. 2007; Bingham and Eisenhardt 2011), building on my work with Donald Sull (Eisenhardt and Sull 2001; Sull and Eisenhardt 2012) and Shona Brown (Brown and Eisenhardt 1997, 1998). Jason Davis, Christopher Bingham and I collaborated on the simulation study (Davis et al. 2009).

Section 2 continues by discussing the broad brush study of how top management teams, markets, and innovation strategies influence entrepreneurial firm performance in the U.S. semiconductor industry. Section 3 describes the in-depth study of strategic decision making by top management teams in the computer industry that was undertaken simultaneously with the first study. Section 4 presents the findings and insights from examining how top management teams learn "simple rules" heuristics, and their strategic and performance implications for entrepreneurial firms while Sect. 5 describes how entrepreneurial top management teams optimally structure their firms at the "edge of chaos" in different types of markets. Section 6 synthesizes the collective results, and offers implications that emerge from this collection of studies.

\section{Top management teams, strategy, markets and performance}

Entrepreneurial firms have a high propensity to fail that has been termed the "liability of newness" (Stinchcombe 1965). This liability occurs for a variety of reasons. For example, entrepreneurial firms often have limited resources that restrict their resilience and ability to adapt. Firm members are new to their roles and relationships with one another, and so are often inefficient and error-prone. Entrepreneurial firms lack "track records" with buyers, suppliers, and other constituents which make it difficult to succeed.

Yet, while the validity of the "liability of newness" has often been empirically demonstrated (e.g., Freeman et al. 1983), this research fails to grapple with a critical observation. There are enormous differences in the performance of entrepreneurial firms. Some young firms become resounding successes and so clearly overcome the "liability of newness". Names such as Apple, Google, and FourSquare come to mind. Yet, others languish or die. Kaye Schoonhoven and I undertook a study to probe why these differences occur.

Our study was novel in its use of growth as the measure of entrepreneurial firm performance. In contrast, many studies look simply at survival or perhaps IPO which are empirically easier to measure and statistically more tractable because they can be represented as $0 / 1$ events. But survival is a crude measure of success, and fails to distinguish between very successful firms and those that cling to life as the "living dead". IPO and other positive exits like acquisition are better measures than survival, but still do not discriminate well among firms (e.g., even weak firms can IPO) and fail to capture relevant differences among top management teams and their investors such as their preferences for liquidity versus control (Wasserman 2003). Our study was also novel in its combining the significant main effects that seem likely to influence performance, including the top management team, market, strategy, and their interactions, in a single study. Thus, we take each of these effects very seriously rather than simply relegating them to statistical controls. This let us more sharply hone in on relative effects.

The research setting is the U.S. semiconductor industry. This is an attractive industry for our research aims for two reasons. First, it has an unusually rich variation in top management teams, i.e., ranging from sole founders with deep technical backgrounds to large and diverse teams with extensive industry experience. Second, it also has rich variation in markets. Indeed, the industry is actually a mosaic of sub-markets such as ASICs, analog, and microprocessors, i.e., some large and some small, some growing and some stagnant, and some highly competitive and some not.

Our data collection involved laboriously gathering both archival and interview data. We used archival data from market research firms for annual information on markets including size, number of competitors, and concentration ratio. We used interviews with CEO's, founders, and other key executives to obtain annual information on the top management team, financial performance, alliance partners, organizational design, and strategy. We worked in pairs with one researcher conducting the interview and the other recording the data and making observations. We assessed the top management teams by measures 
including number of founders, managerial experience, and percentage who had worked together previously. We assessed performance by annual revenue growth, and strategy in terms of the degree to which the firm was engaged in cutting-edge innovation. We supplemented these data with $10-\mathrm{K}$ and annual reports as well as press releases and media coverage. We ended our interviews by asking our informants to discuss the reasons for their success or lack thereof. We were surprised at how little these otherwise knowledgeable executives understood. From their point of view, success was invariably determined by "our terrific people" while failure was driven by bad luck, poor timing, and tough rivals. Our results told a more nuanced story.

First, top management teams have an enormous influence on the success of their entrepreneurial firms. Specifically, larger teams, teams with more diversity in age and experience, and teams with a history of working together were much more likely to launch successful entrepreneurial firms with significant growth (Eisenhardt and Schoonhoven 1990). The underlying reasons include that large (i.e., 4-5 members) and diverse teams simply have more people with more unique skills to do the intense and multi-faceted work of founding a new firm. Teams with some members with extensive industry experience and others without it often bring diverse points of view. Teams that have substantial prior experience with each other seem to have advantages in already having met some of the challenges of working together and indeed having enough experience together to know that they can be effective as a team.

Second, there is a very strong interaction effect between top management teams and markets. That is, entrepreneurial firms with superior teams (i.e., large, diverse age and experience, prior experience together) and in growth markets (i.e., markets with scale that are growing at over 20 percent per year) are likely to perform significantly better than other entrepreneurial firms (Eisenhardt and Schoonhoven 1990). So although the main effects of top management teams and markets are significant, the interaction effects are stunningly strong. In contrast, firms either founded by weak teams (i.e., small and homogeneous with little experience together) or founded in emergent (i.e., new and less than US\$20 million) or mature markets (i.e., large with slow growth) perform less well. Emergent markets are problematic because the timing of their take-off (if ever) can be very long, and entrepreneurs are challenged by the delays and their own limited resources. Mature markets are better in that entrepreneurial firms can sometimes locate very profitable niches such as military products, but these markets are too stable and often locked up by established incumbents. Overall, the combination of a superior team in a great market is over-whelming in its likelihood of leading to high performance. To use a very "California" analogy, it takes a skilled surfer and a huge wave to get a great ride.

Third, founding top management teams and markets are highly predictive of future firm performance. Specifically, small advantages such as a slightly larger team at founding are amplified, not dissipated, over time (Eisenhardt and Schoonhoven 1990). For example, a slightly advantaged firm might get the key alliance partner over a slightly less promising firm. This relationship then leads to more favorable relationships, creating a cascade of advantages. These advantages appeared to compound over time such that performance differences among firms grew not diminished. In addition, these top management teams often set a course at founding that becomes difficult to change as resource commitments, and organizational cultures and structures are locked in. The unexpected insight is that turnarounds are very rare events. Once de-railed, an entrepreneurial firm rarely recovers. Founding conditions are very consequential.

Finally, strong teams and superior markets are almost completely uncorrelated. This surprised us. We expected that strong teams would choose the best markets, but they do not. Rather, founding entrepreneurs typically choose markets that they happen to know because of their own idiosyncratic paths of experiences. This introduces significant luck into the performance equation of entrepreneurial firms.

\section{Top management teams and strategic decision making}

While the broad brush study of entrepreneurial firm performance in the U.S. semiconductor industry described above was ongoing, a much different and more granular study of strategic decision making in the computer industry was also underway. Here, the emphasis is on in-depth and rich field data to explore how top management teams effectively 
(and ineffectively) make the key strategic decisions that shape the trajectories of their firms and, ultimately, firm performance.

A novel feature of this study was its focus on "highvelocity" environments, i.e., settings characterized by rapid, unpredictable, and frequent change around core features such as products, customers, demand, competition, and complementers. Industry structure is fleeting and often unknown. Many entrepreneurs jump into these environments because of the many compelling opportunities that they often provide. Yet, in contrast, prior to this study, most research on strategic decision making focused on not-for-profit contexts like hospitals and universities and on stable industries like chemicals and forest products (Eisenhardt and Zbaracki 1992). The classic models of strategic making that emerged from such studies including bounded rationality, power and politics, and "garbage can" choice did not fit well with high-velocity environments where pace and agility are important, and competition is intense and demanding (Eisenhardt and Zbaracki 1992).

A second novel feature was its use of what became my "signature method", i.e., theory-building from multiple-case studies. I began developing this method in this study, and wrote the related paper on theorybuilding from cases that became very widely cited at this time (Eisenhardt 1989b). This approach to theorybuilding involves inductive reasoning grounded in rich data on the focal phenomenon to develop new constructs and theoretical relationships. It contrasts with other theory-building approaches such as mathematical modeling and "arm-chair" thinking. It is a particularly appropriate methods choice when there is no applicable existing theory. So, it is ideal for opening new areas of inquiry. Multiple cases simply mean using more than one instantiation of the focal phenomenon from which to induct theory. Multiple cases are typically more effective than single cases because they ground the emergent theory in more observations, thus leading to more precise, accurate constructs and theoretical relationships (Eisenhardt 1991). By contrast, single case studies often yield overly complex theories because it is difficult or even impossible to rule out many explanations and to theorize at the appropriate level of abstraction (Eisenhardt and Graebner 2007).

The original plan called for a deductive study using the complete population of about 100 entrepreneurial firms in the "high-velocity" computing industry. But while Jay Bourgeois and I intended to do a deductive, statistical study, we switched to inductive, multiplecase methods early on because the data from the first few firms were so very unexpected and intriguing. We wrote the first academic paper with data from 4 firms (Bourgeois and Eisenhardt 1988), and ultimately studied 12.

The data collection required an intense field effort in which the primary data sources were interviews and observations. We started with an entry interview with the CEO to identify a recent or ongoing strategic decision for in-depth study. This decision had to have high stakes, involve the entire team, and be representative of how the team made its major decisions. We then interviewed all top management team members. We began by asking open-ended questions about topics such as strategy, competition, and interactions among team members. This gave us broad understanding. We then delved into the specific story of each focal strategic decision-concentrating on the timeline of facts and events rather than respondents' interpretations of events and motives of others. We supplemented these data with extensive observations, and questionnaire data on topics such as power, communication, and conflict as well as archival data such as media and press releases, and quantitative data on team demographics and firm financial performance. The result is insights and emergent theory relating the strategic decision making process to performance in entrepreneurial firms.

The overarching insight is that the "trifecta" of speed, conflict, and harmony is at the heart of effective strategic decision making. In particular, the most effective top management teams are fast-i.e., they make critical strategic choices in less than 3 months and often less than 6 weeks-and have very intense conflict about these choices (Eisenhardt 1989a). Yet, they still maintain cordial relationships. In contrast, the least effective teams are slow, i.e., they often take 6 months or more to make the types of strategic decisions that the fast teams can make in under 3 months. Sometimes, these teams have intense conflict, but this conflict is often locked into fixed political factions and becomes personal (Eisenhardt and Bourgeois 1988). Sometimes, teams have little conflict but that is usually indicative of apathy and a false "feel-good" feeling (Eisenhardt et al. 1997). Finally, an effective strategic decision-making 
process ultimately helps to shape superior entrepreneurial firm performance.

While this trifecta is valuable to identify, it is not enough. It leaves open what the teams actually did. For example, how should teams be fast? They could flip a coin, but this clearly sacrifices quality. They might limit the data considered, slash the number of alternatives, and reduce analysis. They might restrict discussion, squash conflict, and centralize the decision. But these too will sacrifice quality, and frustrate key executives. In a series of papers (e.g., Eisenhardt and Bourgeois 1988; Eisenhardt 1989a, 1990; Eisenhardt et al. 1997), we develop an understanding of what more (and less) effective teams do. While there are several relevant behaviors, I focus below on the three most significant ones.

The first is information, i.e., effective top management teams rely on more, not less, information than less effective teams (e.g., Eisenhardt 1989a; Eisenhardt et al. 1997). This was a surprise because prior research argues that comprehensive decision making with extensive data is slow. The key is to realize that this information is a unique type, i.e., real-time information about the external environment such as customers and competitors, and internal operations such as progress against engineering milestones, factory yield, and revenue per employee. Often, this information is quantitative and frequent such as daily bookings and cash flow. Operational measures are preferred over refined accounting-based ones like profit. Moreover, effective top management teams review this information in regular weekly (or even more frequent) meetings with everyone on the team. These teams simply look at more data, more oftenparticularly immediate operating information from inside and outside the firm. As an executive in a very effective team claims, "We over-MBA it!". The result is deep intuition, quick recognition of change, less personalized debate, and greater confidence to act (Eisenhardt 1989a; Eisenhardt et al. 1997).

The second insight is simultaneous alternatives, i.e., effective top management teams rely on more, not fewer, alternatives than less effective teams, and consider them simultaneously, not in parallel (Eisenhardt 1989a; Eisenhardt et al. 1997). Again, this was a surprise, as we had expected that more alternatives would slow the pace and create too much conflict. For example, a very effective team in our study faced a strategic decision to redirect the firm. The team developed multiple alternatives ranging from selling technology, liquidation, entry into a new market, and tactical changes to the current strategy. Intriguingly, team members sometimes consciously introduced alternatives that they did not back in order to expand the set. The result was a more thorough exploration of alternatives that took advantage of the fact that individuals cognitively process faster and with greater confidence when they do so in comparison (Eisenhardt 1989a). Multiple alternatives also improve the likelihood that team members can reach a compromise that all can support, and create a backup position in case the preferred alternative does not work (Eisenhardt et al. 1997).

The third insight is consensus with qualification, i.e., effective top management teams try for consensus, but make the choice if no consensus emerges (Eisenhardt 1989a). Typically, the ultimate decision maker is the executive who is most knowledgeable or most responsible for carrying out the choice. Consensus with qualification relies on clear demarcation of turf, i.e., each team member has the highest power in a few decisions that defined turf while the CEO has the highest average power across all decisions, but highest power for only a few (Eisenhardt and Bourgeois 1988). In contrast, less effective teams use either consensus or fiat, both of which are slow and create interpersonal conflict (Eisenhardt and Bourgeois 1988). Consensus with qualification is effective because it proactively deals with conflict, airs the different views of team members, and provides a path to closure that executives believe is fair, i.e., executives want to be involved, but do not insist on always getting their way (Eisenhardt 1989a; Eisenhardt et al. 1997).

\section{Top management teams and strategy as simple rules}

The research on strategic decision making described above created an understanding of how top management teams effectively make critical decisions. But, these decisions are idiosyncratic choices that rarely repeat. In contrast, top management teams also face many smaller choices around recurring process activities like making acquisitions, developing new products, entering new countries, and hiring employees. But while these activities may occur often, they are not 
routine. The challenge for the top management team is to perform them efficiently while remaining flexible to adjust to the specific circumstances of any particular acquisition, product, and the like.

My initial work with Behnam Tabrizi and Shona Brown examines new product development, i.e., a process that is central to the success of most entrepreneurial firms. One study examines "fast" product development (Eisenhardt and Tabrizi 1995) and the other focuses on developing successive successful products (Brown and Eisenhardt 1997). As we puzzled over the empirical results, Shona and I were frustrated by existing theories and searched for a new lens. We found it in biology with complexity theory and its "edge of chaos" concept. Based on this work, she and I wrote Competing on the Edge: Strategy as Structured Chaos (Brown and Eisenhardt 1997). Donald Sull and I extend these ideas in "Strategy as Simple Rules" (Eisenhardt and Sull 2001, 2012). But while these ideas are grounded in specific companies and real data, they rely on anecdotes and hunches. They needed systematic evidence.

This work sets up the study with Christopher Bingham that fleshes out "strategy as simple rules". We use learning theory as our starting point. The learning literature typically measures accumulated experience of some type with some repeated process like making acquisitions or forming alliances, and then infers that learning occurred when process performance improves. Yet, a striking feature of this research is that it ignores the content of what is learned. Thus, although there is much research that claims that firms and individuals are (or not) learning (e.g., Argote 1999; Haleblian and Finkelstein 1999), learning itself is not assessed. This study is novel in that it measures what individuals actually learn when they gain experience.

The research design combines both inductive, multiple cases, and deductive hypothesis testing. The focal process is internationalization. We sampled 12 entrepreneurial firms in the information technology sector with approximately 70 new country entries. We chose this sector because its many entrepreneurial firms often have global aspirations, making internationalization essential. We studied firms from Finland, U.S., and Singapore to improve the generalizability of the study. We relied on interviews, questionnaires, archival data, observations, emails, and phone calls. We focused on and assessed explicit learning, i.e., what people could articulate that they learned. We did so through responses to an open-end, non-directive request to tell the "story" of a particular country entry, and through responses to explicit questions about what (if anything) had been learned in a particular country that was used elsewhere and vice versa. We determined that learning occurred when multiple informants described the same lessons.

The initial findings mostly confirm what Donald Sull and I had surmised, i.e., people learn "simple rules" heuristics that have a common structure around opportunity capture (e.g., successful country entry) (Eisenhardt and Sull 2001). Specifically, people learn "selection" heuristics that are rules of thumb for guiding what opportunities to pursue (e.g., enter only Asian countries), and "procedure" heuristics that specify how to capture an opportunity (e.g., hire locals to enter). They also learn "temporal" heuristics related to timing such as sequence (e.g., order of approaching customer types), pace (e.g., complete one entry before starting the next) and rhythm (e.g., number of entries per year), "priority" heuristics that are rules of thumb to rank acceptable opportunities (e.g., give preference to Rosetta standard countries), and "exit" heuristics that specify when to stop (e.g., stop pursuing a customer after 3 months without a sale) (Bingham and Eisenhardt 2011). Why these heuristics? They fit the problem-solving context of capturing a flow of similar, but not identical, opportunities.

Our initial findings also confirm that "simple rules" heuristics improve firm performance. Specifically, top management teams that translate their experiences into "simple rules" are more likely to achieve effective performance than teams that just accumulate experience (Bingham et al. 2007). In other words, simply gaining experience does not significantly affect performance unless that experience is sharpened by "simple rules" heuristics. Why are such heuristics effective? They speed action by requiring less information and simplifying cognitive processes. But, a subtler reason is that heuristics are often surprisingly accurate because they exploit information that people have without being explicit about what that information is. For example, one effective top management team in our study had a "simple rule" to only enter English-speaking countries. But, while simple and easy to use, this heuristic also exploits the nuanced cultural and business knowledge of one of the 
founders who grew up in the UK and had much familiarity with the British Commonwealth nations which comprise most English-speaking countries. By contrast, executives, who simply gain experience, often treated each new country as a unique and novel event, and so did not effectively leverage past entries. Rather, they either impulsively went to a country with little thought or engaged in complex, informationintensive analyses to plan their actions. But neither of these approaches is as effective as using heuristics.

But while the study confirmed our expectations, it also broke new ground. First, we find that heuristics are learned in a specific developmental order because some heuristics are easier to learn than others (Bingham and Eisenhardt 2011). Specifically, top management teams learn selection and procedural heuristics quickly, but take longer to learn temporal and priority ones. Exit heuristics are the most difficult to learn. Why is there an order to learning? It appears that it is more challenging to learn heuristics that involve relationships among several opportunities. These heuristics like priority and temporal rules require more cognitive sophistication to learn as people simultaneously must keep in mind information about several experiences while making cognitive links among them. Overall, this developmental order seems to mirror the transition from novice to expert (Ericsson and Kintsch 1995), i.e., in comparison with novices, experts keep more thoughts in mind at once, think in terms of relationships among features like priorities and sequences of activities, and better integrate past and future times. For example, expert firefighters interpret a fire scene by what preceded and what is likely to follow while novices tend to focus on immediate features like color and intensity (Klein 1998). Thus, the later developmental order of learning of priority, temporal, and exit heuristics later than selection and procedural ones is consistent with the transition from novice to expert through accumulated experience.

Second, effective top management teams engage in simplification cycling by which they update their heuristics, but do not increase the number. So, they both elaborate their heuristics as they gain experience, but they also contract them by dropping and simplifying, and by changing abstraction levels (Bingham and Eisenhardt 2011). Simplification cycling is the way in which teams update and improve their heuristics without creating greater complexity. Again, this resembles the transition from novice to expert. For example, studies of experts in bridge, physics, baseball, and electronics all indicate that experts use heuristics based on more abstract and strategic aspects of their situations (Feltovich et al. 2006). So, bridge experts pay attention to the number of cards in each suit which is closely related to winning. Novices track the number of aces played which is easier to remember but less relevant to winning (Charness et al. 2001). Similarly, physics experts rely on general laws like conservation of momentum to solve problems while novices concentrate on superficial features like whether the problem involves a spring or a plane (Chi et al. 1981). Finally, experts are reflective about what and how they know. They keep refining their heuristics even as they keep the number small such that they can improvise flexibly and update their heuristics more effectively (Cowan 2001).

Overall, this study suggests that "simple rules" heuristics and related organizational processes enable top management teams to seize opportunities in an effective and differentiated way. In effect, they are the strategy of entrepreneurial firms and central to the strategic logic of opportunity (Bingham and Eisenhardt 2008). Indeed, heuristics are more "rational" for entrepreneurial top management teams who typically navigate in "high-velocity" environments than the use of extensive information and complex analysis (Bingham and Eisenhardt 2011).

\section{Top management teams and organizational structures at the edge of chaos}

The studies discussed above point to the critical role of top management teams in determining the performance of their entrepreneurial firms, and indicate how these teams do so by making major strategic decisions and learning "simple rules". The fourth study goes a step further to examine how top management teams design effective organizational structures by balancing at the "edge of chaos" (Davis et al. 2009). By structure, we refer broadly to all manner of structures including formalization (e.g., rules and routines), centralization (e.g., hierarchy, verticality), span of control (e.g., scale of sub-units), coupling and structural embeddedness (e.g., tie strength, tie density), and specialization (e.g., role breadth). We define structure simply as constraint on action. 
Prior research across diverse literatures including network theory, strategy, organization studies, and the complexity sciences finds that a balance between too much and too little structure is essential for high performance in dynamic environments (see Davis et al. 2009 for a review). Firms with too little structure lack enough guidance to perform efficiently while firms with too much structure are too constrained and lack flexibility. This suggests an inverted-U relationship between structure and performance. Much research also finds that the optimal amount of structure decreases with increasing dynamism (i.e., inverted-U shifts left) (Davis et al. 2009).

But while these observations appear broadly true, unresolved issues remain. First, the empirical evidence consists of case study and statistical analyses using quadratic terms that are not sufficiently precise to identify specific functional form. Rather, it confirms a unimodal shape, but does not rule out other shapes such as a plateau or an inverted-V. Second, the theory underlying the relationship is incomplete. For example, the theory ignores the downsides of flexibility such as more mistakes and greater need for attention. As a result, the theory fails to clarify precisely the efficiency-flexibility trade-off, including whether there is a skew such that either too much or too little structure is more disadvantageous. Finally, the theory underlying construct of market dynamism is imprecise. Market dynamism is a multi-dimensional construct, and yet the theory does not unpack its dimensions like velocity, complexity, ambiguity, and unpredictability to reveal whether they have distinct or similar effects.

We conducted this research using simulation methods which are effective for research when the basic outline of the theory is understood, but its theoretical logic is incomplete (Davis et al. 2007). Simulation is also especially useful when the focal phenomenon is non-linear, and data (e.g., uncorrelated environmental dimensions and longitudinal effects) are challenging to obtain. Specifically, we use stochastic process modeling. We model the firm as a collection of rules, structure as the number of rules, and environment as a flow of opportunities with varying velocity, complexity, ambiguity, and uncertainty. In each simulation time step, the firm uses a combination of rules and improvised actions to attempt to capture an opportunity. If a sufficient number of actions match the opportunity, the opportunity is captured and performance is increased by the value of the opportunity. The simulation experiments systematically vary the number of rules and the environmental dimensions to determine the effects on performance as measured by the number and value of opportunities captured. We supplement the simulation with a formal mathematical model to sharpen the insights.

A core insight clarifies the tension between efficiency and flexibility. That is, the central trade-off is the flexible capture of widely varying opportunities versus efficient execution of specific opportunities (Davis et al. 2009). Less structure opens the firm to the possibility of capturing a wider range of opportunities that might serendipitously occur. But less structure also takes more time because mistakes are more likely and because individuals have to pay more attention to what to do. Conversely, more structure enables the efficient execution of particular opportunities that are anticipated. But too much structure is more than just too rigid, it narrows the range of possible opportunities, suggesting that structure is most valuable when many similar opportunities exist.

Further, the relationship between structure and performance is actually skewed such that having too little structure is more damaging than having too much (Davis et al. 2009). This occurs because too little structure makes it very difficult to have any traction to accomplish tasks. Top management teams become overwhelmed by mistakes and consumed by figuring out what to do. In contrast, too much structure narrows the range of opportunities, but nonetheless capturing some opportunities very efficiently is still possible. Since entrepreneurial firms typically have little structure, the implication for their top management teams is to structure quickly and more extensively than might seem comfortable to entrepreneurs. Yet, without sufficient structure, these firms may simply not be able to accomplish very much, and so fail.

Finally, the shape of the relationship between structure and performance varies across environments (Davis et al. 2009). In predictable markets, it is a plateau such that the trade-off between flexibility and efficiency is easy to manage. There is a broad range of optimal structures, and it is possible to achieve a stable equilibrium. Here, the entrepreneurial team can be successful with a range of structures from tightly linked activity systems to loosely linked "simple rules". But, in stark contrast, in unpredictable markets, the optimal structure is low, and the relationship 
between structure and performance is an inverted- $\mathrm{V}$ such that there is only a narrow band of optimal structures. Here, it is both challenging and crucial for top management teams to manage the amount of structure. Even minor market changes can be punishing, since performance is precarious and mistakes are many, large, and often fatal. Since entrepreneurial firms often operate in unpredictable markets, the implication is that their top management teams must typically pay particular attention to the amount of structure, focus on real-time improvisation within a few rules, continually recover from mistakes, and quickly exit failing opportunities (Davis et al. 2009).

Other features of the environment are also relevant for top management teams (Davis et al. 2009). Highvelocity markets which are characterized by many rapidly changing opportunities are very favorable environments in which it is possible to have very high performance. The implication for top management teams is to operate quickly. In contrast, complex markets in which teams must perform many tasks well are very unfavorable environments in which performance is usually low. Examples include biotechnology and "green power" which are both technically and institutionally demanding such that entrepreneurs have to be successful in many ways (e.g., technical, safety, manufacturing, government relationships, etc.) to be successful overall. The implication here is to enter with caution. Finally, ambiguous markets such as very nascent ones are especially intriguing. Since they are so hard to interpret, these markets favor luck, and so level the playing field for weaker top management teams. Weaker teams can "win" simply by chance. In contrast, unambiguous markets favor strong top management teams because these are markets in which their skills in managing are more likely to pay off. The implication is that strong top management teams should either try to structure nascent markets to their advantage or avoid them.

\section{Conclusion}

I began by arguing that differences among top management teams often shape the heterogeneous performance outcomes that are observed among entrepreneurial firms in ostensibly similar environments. The aim of the paper is to synthesize several studies that collectively sharpen understanding of the very influential role of top management teams in driving the performance of entrepreneurial firms.

First, top management teams can substantially influence the performance of entrepreneurial firms. In particular, some top management teams are more likely than others to create successful entrepreneurial firms. Such strong teams are typically large, diverse, and have a prior working history together (Eisenhardt and Schoonhoven 1990). Moreover, when these strong teams are in growth markets where there is typically low ambiguity, moderate unpredictability, and high velocity, they are particularly likely to have very high performing firms (Davis et al. 2009). In other words, there is a very strong interaction effect between top management teams and the markets of their firms.

Second, top management teams help their firms to succeed through effective strategic decision making, i.e., decision making that is fast, high conflict, and yet ultimately leaves the cohesiveness of the team intact (Eisenhardt and Bourgeois 1988; Eisenhardt 1989a; Eisenhardt et al. 1997). Such teams make more timely and more effective strategic decisions. But making these idiosyncratic strategic decisions is only part of the story of how top management teams influence the performance of entrepreneurial firms. More effective top management teams are also able to scale more effectively and perform when they use "simple rules" in critical organizational processes such as acquisitions and internationalization as their strategy (Bingham et al. 2007; Bingham and Eisenhardt 2011). Finally, top management teams can influence firm performance by organizing at the "edge of chaos". In particular, top management teams that quickly structure (and even slightly over-structure) their entrepreneurial firms and keep that structure poised at an optimal point gain performance advantages and avoid the "wheel-spinning" that comes with too little structure (Davis et al. 2009).

In conclusion, top management teams-through their composition and their actions-can have a significant influence on the performance of entrepreneurial firms. In such young and small firms, these teams often have greater opportunity to shape the course of their firms than executives of large, established firms. Of course, attractive markets, favorable government policies, and even luck, matter too. But, the point of this article is to remind the reader of the powerful role of top management teams-their composition, strategic choices, ability to learn, and 
organizational skills —in determining the performance of entrepreneurial firms.

Acknowledgments I appreciate the enormous help of my friends and fellow researchers, especially Chris Bingham, Jay Bourgeois, Shona Brown, Jason Davis, Nathan Furr, Kaye Schoonhoven, and Don Sull, in the research discussed here. I also benefitted greatly from the continued support of the Stanford Technology Ventures Program. Finally, I also deeply appreciate the honor of the Global Award for Entrepreneurship Research bestowed on me by the Swedish Entrepreneurship Forum and by the Selection Committee chaired by Professor Bo Carlsson.

\section{References}

Agarwal, R., \& Gort, M. (2002). Products and firm life cycles and firm survival. American Economic Review, 92(2), 184-190.

Argote, L. (1999). Organizational learning: Creating, retaining, and transferring knowledge. Norwell, MA: Kluwer.

Baum, J., Calabrese, T., \& Silverman, B. (2000). Don't go it alone: Alliance network composition and startups' performance in Canadian biotechnology. Strategic Management Journal, 21(3), 267-294.

Beckman, C. M., \& Burton, M. D. (2008). Founding the future: Path dependence in the evolution of top management teams from founding to IPO. Organization Science, 19(1), 3-24.

Bingham, C. B., \& Eisenhardt, K. M. (2008). Position, leverage and opportunity: A typology of strategic logics linking resources with competitive advantage. Managerial and Decision Economics, 29(2-3), 241-256.

Bingham, C. B., \& Eisenhardt, K. M. (2011). Rational heuristics: The "simple rules" that strategists learn from process experience. Strategic Management Journal, 32(13), 1437-1464.

Bingham, C. B., Eisenhardt, K. M., \& Furr, N. R. (2007). What makes a process a capability? Heuristics, strategy and the effective capture of opportunities. Strategic Entrepreneurship Journal, 1(1-2), 27-47.

Bourgeois III, L. J., \& Eisenhardt, K. M. (1988). Strategic decision processes in high velocity environments: Four cases in the microcomputer industry. Management Science, 34(7), 816-835.

Brown, S. L., \& Eisenhardt, K. M. (1997). The art of continuous change: Tying complexity theory and time-paced evolution to relentlessly shifting organizations. Administrative Science Quarterly, 42(1), 1-37.

Brown, S. L., \& Eisenhardt, K. M. (1998). Competing on the edge: Strategy as structured chaos. Boston: Harvard Business School Press.

Charness, N. E., Reingold, M., Pomplun, M., \& Stumpe, D. M. (2001). The perceptual aspect of skilled performance in chess: Evidence from eye movement. Memory and Cognition, 29, 1146-1152.

Chi, M. H., Feltovich, P., \& Glaser, P. R. (1981). Categorization and representation of physics problems by experts and novices. Cognitive Science, 5(2), 121-152.
Cowan, N. (2001). The magical number 4 in short-term memory: A reconsideration of mental storage capacity. Behavioral and Brain Sciences, 24(1), 87-114.

Davis, J. P., Eisenhardt, K. M., \& Bingham, C. B. (2007). Developing theory through simulation methods. Academy of Management Review, 32(2), 480-499.

Davis, J. P., Eisenhardt, K. M., \& Bingham, C. B. (2009). Optimal structure, market dynamism, and the strategy of simple rules. Administrative Science Quarterly, 54(3), 413-452.

Eesley, C. E., \& Roberts, E. B. (2012). Are you experienced or are you talented? When does innate talent versus experience explain entrepreneurial performance? Strategic Entrepreneurship Journal, 6(3), 207-219.

Eisenhardt, K. M. (1989a). Making fast strategic decisions in high velocity environments. Academy of Management Journal, 32(3), 543-576.

Eisenhardt, K. M. (1989b). Building theories from case study research. Academy of Management Review, 14(4), 532-550.

Eisenhardt, K. M. (1990). Speed and strategic choice: How managers accelerate decision making. California Management Review, 32(3), 39-54.

Eisenhardt, K. M. (1991). Better stories and better constructs: The case for rigor and comparative logic. Academy of Management Review, 16(3), 620-627.

Eisenhardt, K. M., \& Bourgeois III, L. J. (1988). Politics of strategic decision making: Toward a mid-range theory. Academy of Management Journal, 31(4), 737-770.

Eisenhardt, K. M., \& Graebner, M. E. (2007). Theory building from cases: Opportunities and challenges. Academy of Management Journal, 50(1), 25-32.

Eisenhardt, K. M., Kahwajy, J. L., \& Bourgeois III, L. J. (1997). Conflict and strategic choice: How top management teams disagree. California Management Review, 39(2), 42-62.

Eisenhardt, K. M., \& Schoonhoven, C. B. (1990). Organizational growth: Linking founding team, strategy, environment and growth among U.S. semiconductor ventures. Administrative Science Quarterly, 35(3), 504-529.

Eisenhardt, K. M., \& Schoonhoven, C. B. (1996). Resourcebased view of strategic alliance formation: Strategic and social explanations in entrepreneurial firms. Organization Science, 7(2), 136-150.

Eisenhardt, K. M., \& Sull, D. N. (2001). Strategy as simple rules. Harvard Business Review, 79, 107-116.

Eisenhardt, K. M., \& Tabrizi, B. N. (1995). Accelerating adaptive processes: Product innovation in the global computer industry. Administrative Science Quarterly, 40(1), 84-110.

Eisenhardt, K. M., \& Zbaracki, M. A. (1992). Strategic decision making. Strategic Management Journal, 13, 17-37.

Ericsson, K. A., \& Kintsch, W. (1995). Long-term working memory. Psychological Review, 102(2), 211-245.

Feltovich, P. J., Prietula, J. J., \& Dricsson, K. S. (2006). Studies of expertise from psychological perspectives. In K. A. Ericsson, N. E. Charness, P. J. Feltovich, \& R. R. Hoffman (Eds.), The Cambridge handbook of expertise and expert performance (pp. 41-68). New York: Cambridge University Press.

Freeman, J., Carroll, G., \& Hannan, M. (1983). The liability of newness: Age dependence in organizational death rates. American Sociological Review, 48(5), 692-710.

Garg, S., \& Eisenhardt, K. M. (2013). Board level strategic decision making: The CEO perspective. Working Paper, Hong Kong University of Science and Technology. 
Gulati, R., \& Higgins, M. C. (2003). Which ties matter when? The contingent effects of interorganizational partnerships on IPO success. Strategic Management Journal, 24(2), 127-145.

Haleblian, J., \& Finkelstein, S. (1999). The influence of organizational acquisition experience on acquisition performance: A behavioral learning perspective. Administrative Science Quarterly, 44(1), 29-56.

Hiatt, S. R., Sine, W., \& Tolbert, P. (2009). From pabst to Pepsi: The deinstitutionalization of social practices and the creation of entrepreneurial opportunities. Administrative Science Quarterly, 54(4), 635-667.

Klein, G. A. (1998). Sources of power: How people make decisions. Cambridge, MA: MIT Press.

Ozcan, C. P., \& Eisenhardt, K. M. (2009). Origin of alliance portfolios: Entrepreneurs, network strategies, and firm performance. Academy of Management Journal, 52(2), 246-279.
Schoonhoven, C. B., Eisenhardt, K. M., \& Lyman, K. (1990). Speeding products to market: Waiting time to first product introduction in new firms. Administrative Science Quarterly, 35(1), 177-207.

Sine, W. D., Haveman, H. A., \& Tolbert, P. S. (2005). Risky business? Entrepreneurship in the new independent-power sector. Administrative Science Quarterly, 50(2), 200-232.

Stinchcombe, A. (1965). Social structure and organizations. In J. G. March (Ed.), Handbook of organizations (pp. 153-193). Chicago: Rand-McNally.

Sull, D. N., \& Eisenhardt, K. M. (September, 2012). Simple rules for a complex world. Harvard Business Review, 90(9), 68-74.

Wasserman, N. (2003). Founder-CEO succession and the paradox of entrepreneurial success. Organization Science, 14(2), 149-172.

Zott, C., \& Amit, R. (2010). Business model design: An activity system perspective. Long Range Planning, 43(2-3), 216-226. 